HID 42 (2015)

\title{
UNA RECETA DE TINTA DE ESCRITURA PROCEDENTE DEL ARCHIVO DE LA CASA DE ALBA
}

\author{
A RECIPE FROM WRITING INK FILE OF THE HOUSE OF ALBA
}

\author{
Teresa María Criado Vega \\ Universidad de Córdoba (España) \\ teresa_criado61@yahoo.es
}

Resumen: La Casa de Alba en su Archivo guarda una receta de tinta negra de la modalidad de las metalogálicas. A lo largo del presente trabajo se han estudiado las materias y procesos, así como se han cotejado con varias recetas castellanas, con igual temática y coetáneas, recogidas en diversos recetarios castellanos depositados en diversos fondos.

Palabras Clave: Archivo de la Casa de Alba, receta, tinta metalogálica, materias, procesos, recetarios castellanos.

ABSTRACT: Archive of the house of Alba keeps a file on your prescription black ink mode of metalogalics. Throughout this work we have studied the materials and processes as well as Castilian been collated with several recipes, and coeval with the same theme, as reflected in various Castilian recipes deposited on different backgrounds.

KEYWORDS: Archive of the house of Alba, recipe, metalogalics ink, materials, processes, castillan recipes.

\section{INTRODUCCIÓN}

Las tintas caligráficas, su composición y elaboración, son uno de los temas que tratan paleógrafos, historiadores del arte e historiadores, entre otros especialistas. Dicho interés no debe causar extrañeza alguna, al tratarse de la materia usada, desde hace varios miles de años, por parte del hombre para expresar a sus semejantes sus pensamientos, ideas y emociones. A lo largo de dichos años se han sucedido varias modalidades, cambios que, en gran medida, han sido motivados por el tipo de soporte escriturario empleado, distinto a lo largo de los siglos.

El primer soporte que usó, conocido hasta la fecha, fueron las paredes de las cuevas, aquí se expresó usando pigmentos, rojos y negros, que le ofrecía directamente la tierra, tierras negras, ocres, rojas; posteriormente olvidó los pigmentos, 
pasando a trazar sus pensamientos en materiales duros, la piedra, por medio de la incisión, pero este material le debió parecer poco idóneo o aplicable solo en casos concretos y pronto buscó otros materiales más idóneos. Dichos materiales, que se sucederían en el tiempo, son el papiro, el pergamino y el papel, el primero procedente del reino vegetal, el segundo del reino animal, y el tercero, en un primer momento, se obtuvo de trapos viejos, y después a partir de la celulosa, todos ellos obtenidos mediante un proceso de transformación, más o menos complejo. Estos soportes, como las cuevas, para recoger las ideas, pensamientos y emociones del hombre exigían dos elementos, uno, un instrumento, que trazara las imágenes, símbolos o ideas y otro, material, que los mostrara, la tinta. Para los dos primeros tipos, papiro y pergamino, se empleó una tinta sencilla de elaborar, carbónica; mientras que para el tercero, papel, se hará con una algo más compleja, la metalogálica.

La tinta es una sustancia más o menos viscosa, formada por materiales que se unen mecánicamente o químicamente al soporte. Dicha adhesión se hace por medio de un instrumento, distinto, según el soporte, pincel, cálamo, pluma, entre otros, el cual además sirve para trazar, escribir o imprimir el mensaje que se desea trasmitir ${ }^{1}$. Las fuentes clásicas, en unas ocasiones, transmiten con gran precisión el nombre y el modo de fabricar las tintas, mientras que en otros casos lo hacen parcamente. En ellas suelen aparecer tres tipos de ingredientes, con funciones bien diferenciadas: un disolvente, un aglutinante y un pigmento, a los que se añade algún ácido, que actúa o debe actuar como un mordiente, penetrando en el soporte y fijándose al mismo ${ }^{2}$. Del primer tipo, el agua es el más habitual, pues a su abundancia y fácil acceso se une una aceptable capacidad química para desleír en él los sólidos más variopintos. Del segundo, destacan las resinas y sustancias gelatinosas de origen animal y vegetal, ellas dan consistencia al producto final, a la vez que facilitan la agregación molecular. El tercero, y último, el colorante, sustancia de origen animal, vegetal y mineral, genera el tono que presenta el preparado o tinta ${ }^{3}$.

De esta composición, en los más de cuatro mil años que se le calcula que tiene de $v i^{4}{ }^{4}$, los hombres han dejado plasmado en numerosas ocasiones el modo de elaborarse, y lo han hecho sobre las diversas tipologías, carbónicas y metalogá-

1. M.E. Rodríguez Díaz, "Técnicas de escrituras y del manuscrito", Historia de la técnica y de la ciencia en la corona de Castilla, tomo II, Edad Media (Coord. L. García - Ballester), Edita Junta de Castilla y León, Consejería de Educación y Cultura, Valladolid, 2002, p. 589.

2. F. Klages, Tratado de química orgánica: Química orgánica sistemática / versión española por Vicente Gómez Aranda, Volumen 1, Parte 1, Barcelona, 2005, p. 519; A. Riesco Terrero, Introducción a la paleografia y la diplomática general, Ed. Síntesis, Madrid, 2000, pp. 262.

3. J. Martínez Maganto, J.L. Ferrero Calabrig, C. Roldán García y J. Álamo Serrano, "Los tituli picti, Estudio sobre el atramentum y su composición", Congreso Internacional Ex Baetica Amphorae, Vol IV, Conservas, aceite y vino de la Betica en el Imperio, Sevilla-Écija, 17 al 20 de diciembre de 1998, Ed. Gráficas Sol, (1998), p. 1222.

4. En la época bíblica se conocía la tinta. Los manuscritos de Qumrán están escritos con tinta no metálica, carbónica (J. Feiner, Mysterium salutis: manual de teología como historia de la salvación, Madrid, 1973, p. 359). 
licas, incorporando dichas descripciones, recetas, a obras y tratados que trataban sobre la escritura ${ }^{5}$ o simplemente se unieron a manuscritos misceláneos.

Esta última realidad es la que hoy nos hace desarrollar el presente trabajo. Se trata de una receta que detalla la forma de elaborar la tinta negra metalogálica, modalidad habitual en los documentos fechados a lo largo de la Baja Edad Media y gran parte de la Modernidad, idónea para el papel, soporte escriturario imperante durante ambas etapas de la historia, y recogida en un manuscrito del Archivo de la Casa de Alba. El manuscrito que la incluye está fechado en el siglo XV y en él se dio cabida a una de las treinta y seis copias que se conocen del tratado de cetrería que hiciera el Canciller Pedro López de Ayala.

Dicha receta, conocida por muchos, llegó a mí hace pocas fechas y como viera que presentaba, al menos aparentemente, ciertas singularidades respecto a las que había analizado de igual tipología, años atrás, decidí hacerme con ella y acometer su examen, cotejándola con alguna de aquellas.

El Archivo de la Casa de Alba, el cual nos acogió durante unos días, es fruto de un proceso de acumulación de documentos procedentes de los distintos títulos o estados nobiliarios que a lo largo de los últimos seis siglos han ido incorporándose a la Casa de Alba. Uno de sus fondos, el más representativo, es el que acoge la obra del Canciller, Fondo de Manuscritos, integrado por más de ciento cincuenta documentos, siendo varios de ellos ejemplares únicos. Entre los manuscritos hay unos, que tienen una enorme trascendencia histórica, mientras otros la tienen desde el punto de vista literario, como le ocurre al que nos atañe, fechándose este en el siglo XV. En el ámbito literario, junto al Libro de la caza de las Aves $^{6}$ del canciller Ayala ${ }^{7}$, destaca El espejo de los Legos, fechado este en el siglo XIV, sendas obras están protegidas por espléndidas encuadernaciones mudéjares; y entre los de carácter histórico cabe reseñar la correspondencia emanada de las embajadas de Gutierre Gómez de Fuensalida, embajador de los Reyes Católicos en Alemania, Flandes e Inglaterra entre 1496 y 1509; la de James Francis FitzJames Stuart, segundo duque de Berwick, embajador en Moscovia en 1727 o la

5. J. Martín, Guía completa de caligrafía: técnicas y materiales, Madrid, 1996, p. 76.

6. En esta obra, redactada durante el cautiverio en Óvidos (Portugal), el Canciller trató de recoger todo el conocimiento práctico que había acumulado a lo largo de su vida sobre el arte de la cetrería. Se conservan unas treinta copias, la mayoría depositadas en la Biblioteca Nacional de España, varias fuera (Gran Bretaña, Francia, Italia, Estados Unidos) y seis en manos privadas, una de ellas la existente en el Palacio de Liria (Madrid).

7. Don Pedro López de Ayala, El Canciller Ayala, fue hijo del matrimonio formado por don Fernán Pérez de Ayala y doña Elvira Álvarez de Ceballos, nació en 1332. No se puede certificar con documento alguno su lugar de nacimiento, aunque los que han estudiado al personaje se decantan por ser originario de Vitoria o la provincia alavesa. Falleció en Calahorra cuando contaba setenta y cinco años de edad. Estaba destinado a la vida eclesiástica pero la muerte prematura del primogénito de la casa hizo que su progenitor cambiase los planes y lo mandase a la corte, siendo paje del rey Pedro, rey al que dejaría años más tarde al convertirse en uno de los seguidores del futuro monarca, Enrique II, con quien llegaría a ser al final de su vida Canciller. Fue coetáneo del famoso historiador árabe, Ibn Jaldun (1332-1406), del destacado cronista de la Guerra de los Cien Años, el francés Jean Froissart (ca. 1337-1404) y del cronista y traductor italiano Filippo Villani (ca. 1325-1407), canciller de Perugia. 
de Fernando de Silva y Álvarez de Toledo, duque de Huéscar, embajador en París entre 1747 y 1753.

El manuscrito que estudiamos tiene como signatura, ms. 94, parece que llegó al Archivo de la Casa de Alba muy prontamente, según se puede desprender de la descripción externa y del ex libris que conserva, desconociéndose el itinerario que siguió hasta llegar a él.

Se encuentra encuadernado en pergamino, el cual parece que se tiñó en azul, estando hoy algo descolorido. El pergamino forra una vieja cubierta de piel marrón realizada sobre papelón. Cinco nervios al lomo. Conserva las tiras del cierre y la solapa para proteger el corte frontal. En la tapa anterior conserva un tejuelo de papel muy descolorido que dice "de Cetrería" y en el interior exhibe el ex libris ${ }^{8}$ de la Casa de Alba. La encuadernación está atacada seriamente por la polilla.

Se trata de un volumen compuesto de noventa y tres hojas de papel, cuatro de ellas están en blanco, concretamente, 29, 44, 45 y 56, que miden 255 x 160 $\mathrm{mm}$., y su caja de escritura de 165 x $90 \mathrm{~mm}$. Estos noventa y tres folios se distribuyen en seis cuadernillos. El texto está escrito por un solo amanuense, siendo la letra elegida la gótica cortesana con cierta influencia humanística. La tinta es color marrón u ocre y presenta letras de mayor tamaño, como única decoración, para la palabra "capítulo", en la tabla y en las rúbricas, y se extiende a las dos primeras palabras de cada capítulo o sección del capítulo octavo. A lo largo del tratado aparecen huecos, destinados, probablemente, para dibujar las iniciales de los capítulos.

Con relación a la conservación del documento, no es buena, y está rasgado el folio 1; desde este hasta el 5 y del 14 al 16 así como del 75 al final muestras orificios de polilla, mostrando mayor daño y gravedad para el texto a partir del folio 75 .

Al tratado de cetrería que abarca los primeros noventa y un folio, iniciándose, concretamente, en el folio 1r, le siguen trece recetas, ocho copiadas por el mismo escribano que el resto de la obra. Una mano posterior añadió las otras cinco. Las recetas describen remedios para aves y humanos ${ }^{9}$. La receta de tinta aparece en el folio $91 \mathrm{v}^{10}$.

8. Un ex libris es una marca de propiedad que habitualmente consiste en una estampa, etiqueta o sello que suele situarse en el reverso de la cubierta de un libro, y que recoge el nombre del dueño del ejemplar o de la biblioteca propietaria. El nombre del poseedor va precedido normalmente de la expresión latina ex libris, ex biblioteca o ex libris, entre otras expresiones que vienen a significar "soy de", (DRAE).

9. Gargarismos para / la flema y para el dolor de la muela (f. 93r).

10. J.M. Fradejas Rueda, "De nuevo sobre los manuscritos del Libro de la caça de las aves de Pero López de Ayala", Lengua Viva: Homenaje a César Hernández Alonso, Universidad de Valladolid - Diputación de Valladolid, Valladolid (2008), pp. 1101-1102. 


\section{LAS TINTAS METALOGÁLICAS}

Se desconoce el momento exacto en que se empezaron a usar las tintas ferrogálicas, cuprogálicas, taninas o caparrosa ${ }^{11}$. Es la tinta elaborada con metal y agallas, siendo el metal, generalmente, hierro; se hace mezclando ambas (sulfato de hierro o caparrosa más una solución de ácido tánico) y, además, se le suele agregar goma, siendo la función de la cola la de coagulante más que la de adhesivo. El color negro es el resultado de una reacción química ${ }^{12}$.

El principio químico para la obtención de una coloración negra a partir de la reacción entre una sustancia tánica y una sal metálica era bien conocido en el Egipto faraónico, donde se usaba entonces para el curtido de las pieles y en la tintura de las lanas y de los tejidos ${ }^{13}$. El empleo del tanino en el mundo de la escritura lo comenta Filón de Bizancio (siglo III a. C.), concretamente, cuando nos habla de una tinta simpática de origen metálico ${ }^{14}$. Siglos después, Dioscórides en su obra De materia médica, libro V, capítulo 96, "De la tinta para escribir", incluye un testimonio que respalda la idea de que en época Antigua, ya se usaban estos ingredientes en el proceso de elaboración de la tinta ${ }^{15}$.

Redundando en la teoría de que se ignora el momento exacto del inicio del uso de este tipo o modalidad de atramentum, pues, como se ha dicho, se tienen noticias de la existencia de una receta de tinta metálica en el siglo III a. C., Plinio en su Historia Natural (siglo I d. C.), alude a un líquido negro obtenido a través de una solución de sales de hierro mezclada con nueces de agalla y cáscara de granada triturada. Tiempo después, el Papiro de Leiden (siglo II d. C.) y San Isidoro de Sevilla (siglo VI), informan del uso de las agallas y del vitriolo, sales, en la elaboración de un tipo de tinta.

Pero a pesar de lo dicho, hasta el momento, la producción y difusión del proceso a seguir para obtener esta modalidad de tinta, no se dará hasta el siglo XII. A partir de esta centuria, recetarios y otros tipos de texto incluirán recetas que nos describirán el proceso y las materias. El punto de partida de esta eclosión parece que fue Schedula diversarum artium, obra de Teófilo, quien a juicio de los investigadores era un hermano o monje del scriptorium de Reichenau ${ }^{16}$. En el capítulo treinta y ocho, dedicado a la tinta (encaustum), Teófilo comenta que a la infusión de tanino, obtenida mediante la maceración del espino albar, se ha de sumar una

11. En la época bíblica se conocía la tinta tanto metálica como carbónica (Jr. 36, 18) (J. Feiner, Mysterium salutis: manual de teología como historia de la ..., p. 359).

12. C. de Hamel, Copistas e iluminadores. Artesanos Medievales, Madrid, 1997, pp. 27-44; E. Primo Yúfera, Química orgánica básica y aplicada: de la molécula a la industria, Vol. 1, Barcelona, 1994, p. 717.

13. A. Vian Ortuño, Introducción a la química industrial, Barcelona, 2006, p. 456.

14. E. Pérez Herrero y B. Rivero Suarez, Escritura manuscrita y procesal: Canarias en el siglo XVI, Las Palmas de Gran Canaria, 2006, p. 52.

15. Dioscórides, Plantas y remedios medicinales, introducción, traducción y notas de Manuel García Valdés, Madrid, 1998, p. 253-254.

16. E. González-Alonso Martínez, Tratado del dorado, plateado y su policromía: tecnología, conservación y restauración, Valencia, 1997, p. 45. 
sal metálica ${ }^{17}$. Un siglo después, las recetas relativas a la forma de elaborar las tintas metalogálicas eran numerosas, incluyéndose en cualquier tipo de texto $\mathrm{u}$ obra, entre los muchos ejemplos localizados destacan, de una parte, las incluidas en el "Llibre de contemplación" de Ramón Llull; en "Tirant lo Blanch", cap. 289, y la atribuida erradamente a San Alberto Magno, "De rebus metalicis, De cose minerali e metalliche, libri $5^{\mathrm{m} 18}$; $\mathrm{y}$, de otra parte, las incorporadas en varios códices italianos, Códice misceláneo 87 del archivo de la catedral de Vercelli, el Códice 490 del archivo de la Biblioteca Capitular de Lucca, el Códice Vaticano Reginense Latino 124 de la Biblioteca Vaticana y el Códice de Paume 407, $2^{19}$.

Sobre el cambio de tinta, carbónica a metalogálica, se puede decir que todas las noticias nos llevan a creer que se dio a la vez que se pasaba del pergamino al papel como soporte escritorio ${ }^{20}$. Este tipo de tinta ofrecía una buena adherencia al papel y presentaba una buena tonalidad negra. Además, esta tipología era fácil de elaborar y sus ingredientes eran asequibles tanto en el comercio municipal como en el regional. La difusión de su uso, además, permitió el empleo de la pluma en detrimento del cálamo, ya que la nueva tipología presentaba mayor fluidez, circunstancia que permitía escribir con mayor celeridad que las carbónicas. En relación al nuevo soporte, ellas se acomodaron mejor que las carbónicas, aunque presentaban ciertos inconvenientes, como era que para enmendar las erratas se tenía que usar un objeto cortante, y no una simple esponja humedecida, sistema que se aplicaba para hacer las correcciones en el caso de la carbónicas, o los problemas relativos a la conservación de los documentos ${ }^{21}$.

\section{La receta del manuscrito 94 del Archivo de Alba y los Recetarios CASTELLANOS}

Las tintas metalogálicas, tipología a la que se adscribe la receta existente en el Archivo de Alba, objeto del presente trabajo, consiste en un extracto vegetal rico en taninos que, al mezclarse con el sulfato de hierro, logra producir un intenso tono negro ${ }^{22}$. El colorante en este tipo de tinta procede de la reacción química de un ácido con un metal en el soporte de la escritura. El ácido oxida el papel generando el color de la tinta y muerde materialmente al soporte que impregna, y lo hace de tal modo que lo anotado no se borra en caso de que le caiga agua. Algunas

17. Theophilus, On Diver arts, Nueva York, 2012; R. Guareschi, Tintas de escribir, Barcelona, 1920, p. 4.

18. Mà. Cárcel Ortí y J. Trenchs Odena, "La tinta y su composición. Cuatro recetas valencianas (siglos XV - XVIII)", Revista de Archivos, Bibliotecas y Museos, 82, 1979, pp. 419 - 420.

19. Persee, "Anciennes recettes d'encre", Bibliothèque de l'école des Chartes, 72, 1911, pp. 437-438.

20. J. Martin, Guía completa de caligrafia: técnicas y..., pp. 57-86.

21. C. Morterero y Simón, Apuntes de iniciación a la paleografía española de los siglos XII a XVII, Madrid, 1979, pp. 20-21; C. de Hammel, Copistas e iluminadores. Artesanos ..., pp. 27-44.

22. P.J. Quetglas, Elementos básicos de filología y lingüística latinas, Barcelona, 2006, p. 27. 
veces se le suma negro de humo para mejorar su coloración inicial antes de la reacción química ${ }^{23}$. Entre sus ingredientes se distinguen sustancias básicas y aditivas.

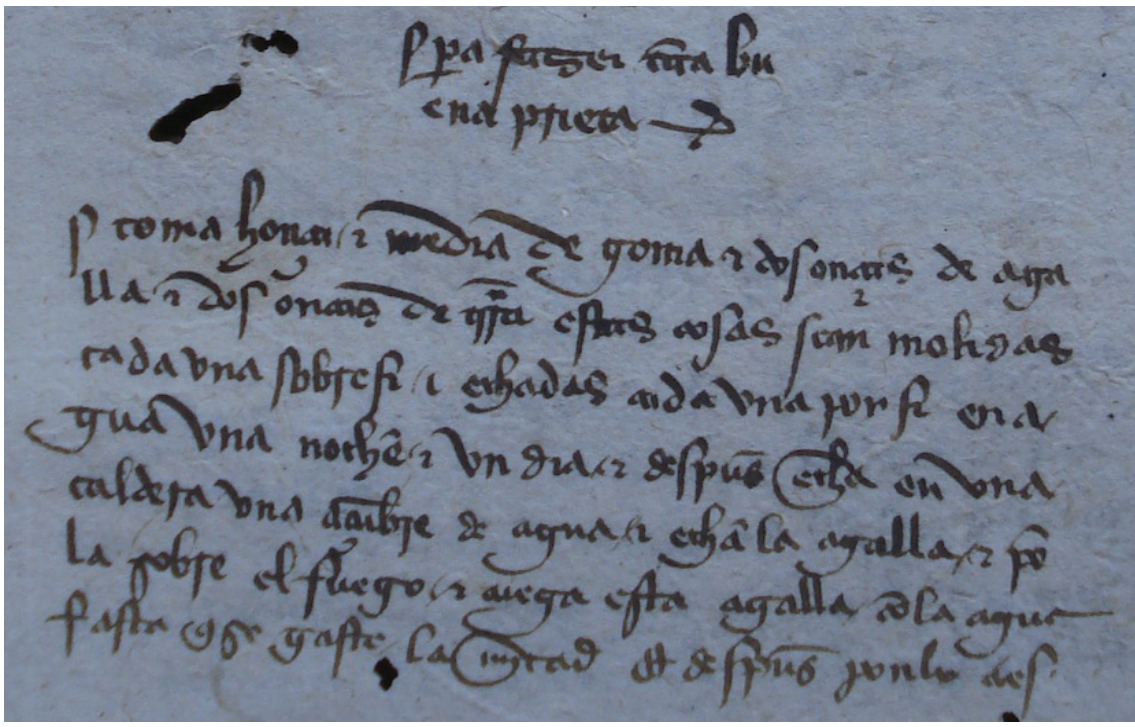

"Para fazer tinta buena prieta", Archivo de la Casa de Alba (ms. 94, fol. 91r). Siglo XV

La receta del Archivo de la Casa de Alba incluida, como ya hemos comentado, en el manuscrito 94 del Fondo de Manuscritos, titulada "Para fazer tinta buena prieta", presenta, de una parte, grandes similitudes con recetas sobre la misma cuestión localizadas en diversos recetarios castellanos ${ }^{24} \mathrm{y}$, de otra parte, ciertas diferencias. Las semejanzas se dan principalmente en el capítulo de las materias, esta, como aquellas, presenta los ingredientes básicos, sustancia tánica, agallas, sal metálica, aglutinante y disolvente, sin embargo en ella no aparece ninguna de las sustancias aditivas. Las diferencias, por su parte, se producen en los procesos, siendo, esencialmente, meras matizaciones.

23. M. Doemer, Los materiales de pintura y su empleo en el arte, Ed. Reverte, Barcelona, 2005, p. 316; M. Romero Tallafigo, Arte de leer escrituras antiguas, paleografía de lectura, Huelva, 2003, p. 45 .

24. Biblioteca Nacional de España (BNE), ms. 9226; Biblioteca del Palacio Real (BPR), ms. II/1393(6); Biblioteca de la Real Academia de la Historia (BRAH) "Fondo Salazar y Castro", ms. K 50; Biblioteca de la Universidad de Salamanca (BUS), ms. 354; Biblioteca de la Facultad de Medicina de Montpellier (BFMM), ms. H - 490 (R. Córdoba de la llave, "Un recetario técnico castellano del siglo XV, el manuscrito H - 490 de la Facultad de medicina de Montpellier", La España Medieval, 2005, 28, pp. 46 - 47). 
Los ingredientes que se incluyen en la receta son, concretamente, agallas, tierras, goma y agua. Los procesos que se dan son molienda, remojo, cocimiento y exposición de la confección al sol, maceración.

Respecto a los ingredientes, tanto nuestra receta como las encontradas en los manuscritos castellanos, a partir de ahora las llamaremos "recetas castellanas", coinciden en la inclusión de las nueces de agallas, como materia que aporta el tanino. Dicha presencia nos informa de que estamos, en unos casos y otros, ante fórmulas adscritas a la zona occidental de Europa así como que tienen influencia árabe. Frente a esta realidad, las recetas del ámbito del norte de Europa recogen en lugar de las agallas frutos, madera y corteza de varias plantas (leño espinoso, encina, castaño), hollejos de vino, cáscara de granada, algarrobillas, mirobálano, madreselva, alumbre, sal amoniaco, bayas y mirto ${ }^{25}$. La aplicación de las nueces, en el Occidente europeo, de un modo constante, se dio a partir del siglo XIII, reemplazando a otras, como por ejemplo, la madreselva o el mirobálano. Esta utilización se debió al alto contenido que tienen las agallas de ácidos tánicos, lo cual las hacía ideales para reaccionar con más cantidad de hierro y obtener así una coloración negra más intensa. En España, se usaron con continuidad, siendo la causa, razones climáticas así como la influencia árabe ${ }^{26}$.

En segundo lugar, las sales metálicas. En este punto antes de nada se debe hacer la siguiente advertencia: en la receta objeto de estudio al citar este ingrediente no aparece ni acije, ni caparrosa, ni vitriolo, así como tampoco ninguno de los vocablos que encontramos en otros casos, sino "tierras". Fue esto, lo que a priori me sorprendió y me hizo analizar la fórmula. Concretamente, me hizo preguntarme si se trataba de un error o de una novedad respecto a las materias que había encontrado en otras recetas. Después de una labor de búsqueda pude identificar "tierras" con "caparrosa", uno de los nombres que se le da a las sales, según hemos señalado anteriormente. Dicha constatación me vino de la localización de dos recetas de tintas, coetáneas a la de Alba, anotadas por el notario gallego, Álvaro Peres. En ambas, el notario al aludir a las sales habla de caparrosa o "tierras"27. Según esto, nuestra receta al referirse a "tierras" está sugiriendo vitriolo o una materia que hace las mismas funciones que la caparrosa. Por su parte, las recetas castellanas cuando nombran a las sales metálicas, tampoco son claras, así, si la receta de Alba las denomina como "tierras", aquellas, según los casos, las nominan como acije, caparrosa, vitriolo, etc.; dichos términos, acije, caparrosa, vitriolo, hacen referencia indistintamente a dos sulfuros, cúprico y ferroso, los cuales muchas veces no se pueden identificar, a menos que en la receta, en nuestro caso castellana, se especifique el color, verde o azul, para la elaboración de las tintas se prefería el

25. S. Kroustalis, "La Escritura y sus materiales, pigmentos, tintas e instrumentos", El soporte de la lengua, Coord. M. C. Hidalgo Brinquis, Nájera 22-26 de septiembre 2003, Patronato de Santa María la Real de Nájera, Logroño, 2008, p. 150.

26. M.C. Hidalgo Brinquis, "El papel de los manuscritos árabes e hispanoárabes: características materiales", Al-mahțuttä̈ al- 'arabiyä̈ fì isbaniya wa al-Magrib, Ed. María Jesús Viguera, Concepción Castillo Castillo, Fundación El Legado Andalusí, Granada, 2006, pp. 300-301.

27. T. Plaza, Libro de notas de Álvaro Pérez, notario de terra de Rianxo e Postmarcos (1457), Santiago de Compostela, 1999, p. 337. 
verde, sulfuro férrico. El vitriolo verde daba una tinta más fluida, más estable en la suspensión de sus partículas, aunque su negro resultaba menos intenso que el que proporciona el cobre, y para solventar este pequeño problema se usaban colores naturales.

En el tercer puesto aparecen los aglutinantes, colas de origen animal o vegetal, impiden que las sales formen grumos o se depositen como poso en el fondo del tintero, entre ellas destacan la goma, miel, clara de huevo, aceites u óleos. La receta de Alba recoge la goma, siendo esta la materia habitual que encontramos ${ }^{28}, \mathrm{y}$, normalmente, al ser citada en la documentación lo hace no como "goma ", a secas, como ocurre en la receta que analizamos, sino como "goma arábiga"; pero, no podemos afirmar que en todos y cada uno de los casos en los que aparece "goma arábiga" en las fuentes se trate de aquella resina que deriva de la acacia, pudiéndose afirmar, en consecuencia, que "goma arábiga" era una forma elegante de citar al aglutinante ${ }^{29}$.

El cuarto y último ingrediente, el agua, el disolvente, facilita la mezcla de forma homogénea de las materias o los principios activos de las mismas, es el que aparece en la receta que analizamos sin especificar si esta debe ser de lluvia, río, cisterna o pozo. También podía usarse vino (blanco o tinto), cerveza, vinagre o mezcla de varios de ellos. Dichos líquidos, excepto la cerveza, aparecen en las recetas castellanas, en unas ocasiones se citan unos, mientras que en otras se anotan otros disolventes. El vino iba como disolvente del tanino, así como también como secador de la tinta, como todo alcohol, y como conservante de la goma arábiga; el vinagre como antiséptico contra los mohos que se podían generar con el tintero abierto o en la misma escritura ${ }^{30}$. El vino se recomendaba para aquellos casos en los que iba a escribirse en pergamino y para textos de calidad, esta recomendación se hacía debido a que el color que se lograba era más intenso y, además, la tinta obtenida resultaba más permanente. Ignacio Pérez, calígrafo madrileño, nacido en 1574 e hijo del maestro Juan Pérez ${ }^{31}$, entre otros, recomendaba usar esta tinta en los fríos meses de invierno, probablemente debido a que el alcohol del vino funciona como anticongelante. El agua se empleaba, por su parte, para hacer la tinta común, para escribir en papel y en los calurosos meses de verano, pues ella se evapora más lentamente que el vino ${ }^{32}$.

Junto a estos ingredientes, en algunas recetas castellanas, no en la de Alba, aparecen los aditivos, su fin era modificar alguna de las características de la tinta. Asimismo se podía añadir, según el gusto de los calígrafos, cortezas de granada, un poco de tinta de carbón u otros colorantes (índigo, añil) para mejorar la intensidad del color, e incluso materias olorosas, como por ejemplo, agua de olor, resinas

28. A. García Cuadrado, Las cantigas: El códice de Florencia, Murcia, 1993, p. 38.

29. En las recetas castellanas aparece indistintamente goma arábiga o goma.

30. M. Romero Tallafigo, Arte de leer escrituras antiguas..., p. 45.

31. J.C. Galende Díaz, "La escritura en España durante el siglo XVI: Génesis y evolución de la caligrafía",. Disponible en humanismo http://ww.tribunalqro,gob.mx/humaniverso/articulos. php?login_autorjuancarlos, p. 7.

32. $\overline{\mathrm{S}}$. Kroustallis, "Escribir en el siglo XVI, recetas de la tinta negra española", Torre de los Lujanes, Boletín de la Real Sociedad Económica Matritense de Amigos del País, 48, 2002, pp. 99 - 112. 
odoríferas $^{33}$. Las cortezas de granada dan brillo a la tinta y, además, añaden a la confección más sustancias tánicas. El palo de la higuera era el más recomendado para mover la tinta mientras se dejaba reposar.

En la receta de Alba las cantidades del tanino, tierras y goma vienen expresadas en onzas, mientras que el disolvente, agua, lo hace a través del azumbre. Esta misma realidad, se observa en las recetas castellanas, en ellas, efectivamente, las cuantías que se precisan de taninos, metales y aglutinantes suele venir expresadas en onza, además de la la libra; y los líquidos o disolventes a través del citado azumbre $^{34}$, además del cuartillo, la libra y la onza. Mientras que los aditivos, ausentes en nuestra fórmula, se expresan, frecuentemente, bajo expresiones, tales, como una avellana, un poquito, un puñado o una unidad ${ }^{35}$.

En general, se puede afirmar que entre las materias representan mayor porcentaje los básicos, es decir, taninos, metales o sales, aglutinantes y disolventes, mientras que la aportación de los aditivos es en muchos casos residual o inexistente. El peso que se exigía de agallas y vitriolo, según vemos en la receta que analizamos y en las castellanas, solía ser elevado, mientras que de aglutinante, goma, se solía usar una menor cantidad. Los ingredientes aditivos, por su parte, representaban menor porcentaje, aun, que la goma ${ }^{36}$.

El proceso de elaboración de la tinta, por lo común, se iniciaba con la introducción de las agallas en un disolvente, en el caso de la receta que nos ocupa en agua, pudiendo ser, como hemos dicho, también vino, donde debían permanecer en reposo durante cierto número de días, pasados los cuales al líquido obtenido (a veces se sacaban las agallas) se le agregaban los restantes ingredientes. En otros casos, minoritarios, se incorporaban todos los ingredientes a la par, para dejarlos en reposo ${ }^{37}$ o para exponerlos al sol ${ }^{38}$. Es decir, la extracción de los taninos de las agallas se podía realizar mediante su maceración en agua o vino, o a través de cocimiento, siendo la cocción el modo más rápido. En nuestra receta, así como en las castellanas, es la maceración, mientras que en las que conocemos del norte de Europa se opta por la cocción. Con la maceración se consigue extraer más sustancia tánica y, además, se logra un color negro más intenso, sobre todo si, además, se dejaba oxidar antes de usarse. El tiempo de maceración es variable, siendo menor con el vino, pues el alcohol facilita la extracción de los taninos. Una ligera cocción

33. E. Ruiz García, Manual de Codicología, Madrid, 1988, p. 165.

34. En varias recetas castellanas las cantidades que se citan son las necesarias para hacer un azumbre (Medida de capacidad para líquidos, que equivale a unos dos litros, DRAE) de tinta.

35. BNE, ms. 9226, "Tinta negra", p. 106; BUS, ms. 354, "Receta de tinta", f. 225v; Libro de los Oficios del monasterio de Guadalupe Receta 3, "Reçebta para hazer tinta sin fuego para letra y punto grueso en pergamino", f. 203r-v (Libro de los oficios del monasterio de Nuestra Señora de Guadalupe, Volumen I, dirigido y coordinado por M. L. Cabanes Catalá, Badajoz, 2007, p. 370).

36. BNE, ms. 9226, "Recepta para tinta negra para papel y para pergamino",p. 35; Libro de los Oficios del monasterio de Guadalupe Receta 3, "Reçebta para hazer tinta sin fuego para letra $y$ punto grueso en pergamino", fol. 203r-v (Libro de los oficios del monasterio de Nuestra Señora de Guadalupe, Volumen I..., 2007, p. 370).

37. BPR, ms. II/1393, "Tintas", f. 1r.

38. BNE, ms. 9226, "Tinta negra", p. 106. 
se solía hacer al final del proceso, y se hacía para mezclar mejor los ingredientes, así como, para darle más brillo a la tinta ${ }^{39}$.

Una vez obtenido el líquido de las agallas, con independencia de que las nueces se sacaran o no, los ingredientes se incorporaban a aquel, variando según los casos, es decir, todos a la vez o sucesivamente. Seguidamente, la confección se exponía al calor, del sol ${ }^{40}$ o del fuego manso de carbón (tintas en caliente) ${ }^{41}$, o simplemente se dejaba en reposo ${ }^{42}$. Acometida alguna de las operaciones señaladas, se obtenía la tinta, y a continuación, según el gusto, se colaba o no, guardándose en un recipiente idóneo, tintero, vejiga, frasco, $\mathrm{u}$ otro.

En lo que se refiere al tratamiento recibido por las agallas, en la mayor parte de las recetas se indica que se dejen en remojo a lo largo de varias jornadas, previas al momento de iniciarse el proceso de elaboración de la tinta ${ }^{43}$. En otros casos, minoritarios, todos los ingredientes se incorporaban a la vez, en el mismo recipiente, con el disolvente, agua o vino ${ }^{44}$. En varios ejemplos, uno de ellos la receta de $\mathrm{Alba}^{45}$, no sólo eran las agallas las que se ponían en remojo previo, sino también otras sustancias, poniendo cada una de ellas en distinto recipiente, y repartiendo el disolvente (vino o agua) en tantas vasijas como sustancias se ponían en remojo ${ }^{46}$.

En varias recetas se advierte que concluido el plazo de tiempo que han de estar en remojo las agallas, éstas deben retirarse, concretamente, antes de proceder a incorporar los restantes ingredientes en la confección obtenida ${ }^{47}$. En otras, se afirma que la confección o líquido obtenido de las agallas más el disolvente debe ser

39. S. Kroustallis, "Escribir en el siglo XVI, recetas de la tinta..., pp. 99 - 112.

40. Tintas en frío, en BNE, ms. 9226, "Recepta para tinta negra para papel y para pergamino", p. 35; "Tinta negra", p. 71; "Tinta negra", f. 106; "Tinta negra", p. 112.

41. BNE, ms. 9226, "Para hacer tinta negra buena", p. 41 y "Para hazer tinta para escribir en toda perfección buena", p. 161; BRAH "Fondo Salazar y Castro", ms. K-50, "Receta de tinta", f. 150r; Libro de los Oficios del monasterio de Guadalupe, Receta 1, "Recebta para hazer tinta", f. 202r-v (Libro de los oficios del monasterio de Nuestra Señora de Guadalupe, Volumen I..., p. 368); BFMM, ms. H-490, "Para tinta" (R. Córdoba de la llave, "Un recetario técnico castellano del siglo XV..., pp. 46 - 47).

42. Libro de los Oficios del monasterio de Guadalupe, Receta 2, "Recebta para hazer tinta sin fuego para el papel o pergamino delgado", f. 202r-v y Receta 3, "Reçebta para hazer tinta sin fuego para letra y punto grueso en pergamino", f. 203r-v (Libro de los oficios del monasterio de Nuestra Señora de Guadalupe, Volumen I..., pp. 369- 370).

43. BNE, ms. 9226, "Recepta para tinta negra para papel y para pergamino", p. 35; "Tinta negra", "Para hacer tinta negra buena", p. 41.

44. BPR, ms. II/1393(6), "Tintas", f. 1v; BNE, ms. 9226, "Tinta negra", p. 106; "Tinta negra", p. 112.

45. En la receta de Alba se introducían, una vez molidos, en agua, separadamente, la tierra, las agallas y la goma y luego posteriormente se iban sumando al líquido donde estaban las agallas los demás ingredientes.

46. Libro de los Oficios del monasterio de Guadalupe, Recetas 1, "Recebta para hacer tinta", f. 201r-v; Receta 2, "Recebta para hazer tinta sin fuego para el papel o pergamino delgado", f. 202r-v y Receta 3, "Reçebta para hazer tinta sin fuego para letra y punto grueso en pergamino", f. 203r-v (Libro de los oficios del monasterio de Nuestra Señora de Guadalupe, Volumen I..., pp. 368-370).

47. BNE, ms. 9226, "Recepta para tinta negra para papel y para pergamino", p. 35; "Tinta negra", p. 71, "Tinta negra", p. 106 y "Tinta negra", p. 112; BRAH, ms. K-50, "Receta para hacer tinta", f. 146r v; Cuando se habla aquí de confección estamos refiriéndonos al líquido obtenido tras permanecer en remojo las agallas en el respectivo disolvente. 
expuesto al fuego para obtener un preparado más concentrado ${ }^{48}$. En la del Archivo de Alba, las agallas, después del citado remojo, se ponen a hervir, y una vez que merme el agua aproximadamente la mitad se ha de retirar la olla, y se deja enfriar. En una receta ${ }^{49}$, se indica que las agallas han de freírse antes de hacerlas fermentar en el disolvente y, en otra ${ }^{50}$, que las hematites deben de ser diluidas en vino (disolvente) antes de añadirse a la confección.

En cuanto a la caparrosa, vitriolo o tierras, como las nombra nuestra receta, es frecuente que se aconseje su incorporación al proceso una vez que se dispone del preparado obtenido del disolvente más el tanino ${ }^{51}$. Esta sal o sulfuro en una receta castellana, así como en la de la casa de Alba, se señala que se añada el vitriolo, una vez incorporada la goma. En otro ejemplo, se indica que sólo se sume la sal a la confección obtenida, se le deje reposar un tiempo y, posteriormente, se añadan los restantes ingredientes ${ }^{52}$. En dos casos, las tierras se incorporan a la vez que la goma, en el primero, una vez que la resina ha estado en remojo ${ }^{53}$; y, en el segundo caso, tras haber estado la goma en remojo, expuesta al sol, haber sido molida, metida en un paño y colgada de un hilo, esta y las tierras se introducen en la vasija junto con los ingredientes ya incorporados, se pone el recipiente con todos ellos sobre el fuego, donde permanecerán hasta que la mezcla haga un poco de espuma ${ }^{54}$.

En cuanto a los aglutinantes, concretamente, la goma, en algunas ocasiones, se apunta el tratamiento a que ha de ser sometida, antes de incorporarse al proceso de elaboración de la tinta, concretamente, pulverizada, remojada, deshecha o moli$\mathrm{da}^{55}$. En la receta de Alba, específicamente, se dice que se ponga a remojar en agua a lo largo de una jornada y media. En cuanto al momento de su incorporación en el proceso las recetas citan momentos distintos ${ }^{56}$, así vemos aquella en que se indica que se añadirá una vez que las agallas han permanecido en remojo ${ }^{57}$, aquella otra que señala que se añadirá al final junto con la caparrosa ${ }^{58}$, y la de Alba que dice que se agregue después de haber incorporado las agallas, luego de haber hervido

48. Libro de los Oficios del monasterio de Guadalupe, Receta 1, "Recebta para hacer tinta", $\mathrm{f}$. 201r-v (Libro de los oficios del monasterio de Nuestra Señora de Guadalupe, Volumen I..., p. 368).

49. BNE, ms. 9226, "Para hazer tinta para escribir en toda perfección buena", p 161.

50. BUS, ms. 354, "Receta de tinta", fol. 225v.

51. BPR, ms. II/657, "Para hacer tinta sin fuego", f. 24r; BNE, ms. 9226, "Tinta negra", p. 35; "Tinta negra", p. 71 y "Tinta negra",p. 112, "Para hazer tinta para escribir en toda perfección buena",p. 161.

52. BNE, ms. 9226, "Tinta negra", p. 106, "Para hacer tinta negra buena", p. 41.

53. BRAH, ms. K-50, "Receta de tinta", f. 146r; Libro de los Oficios del monasterio de Guadalupe, Recetas 1, "Recebta para hazer tynta", f. 201rv-v; Receta 2, "Recebta para hazer tinta sin fuego para el papel o pergamino delgado", f. 202r-v (Libro de los oficios del monasterio de Nuestra Señora de Guadalupe, Volumen I..., pp. 368- 370); BFMM. ms. H-490, "Para tinta" (R. Córdoba de la Llave, "Un recetario técnico castellano del siglo XV..., pp. 46 - 47).

54. BUS, ms. 354, "Receta de tinta", f. $225 \mathrm{v}$.

55. BNE, ms. 9226, "Recepta para tinta negra para papel y para pergamino", f. 19.

56. BPR, ms. II/1393, "Tintas", f. 1v.

57. BNE, ms. 9226, "Tinta negra", p. 71 y "Tinta negra", p. 112.

58. BNE, ms. 9226, "Para hazer tinta para escribir en toda perfección buena", p. 161 r-v, "Tinta negra", p. 106. 
estas hasta mermarse el agua la mitad, y antes de añadirse las tierras, sales, es decir, después de los taninos y antes de las sales, mediando, entre una incorporación y otra, un cocimiento.

El disolvente o el líquido al que se incorporan las agallas para obtener la mezcla a la que se sumarán los restantes ingredientes era normalmente el agua, por su abundancia y fácil acceso, sin embargo, en las recetas castellanas, lo habitual es el vino ${ }^{59}$. Dentro de éste, aparece citado con mayor asiduidad el blanco ${ }^{60}$, y con menor frecuencia el tinto, en ocasiones puntuales, también, se incluyen las cualidades que debe tener, joven, suave o flojo ${ }^{61}$. El agua, como sabemos, aparece en contadas ocasiones en las recetas castellanas, la de Alba recoge, precisamente, el agua, pero no concreta la modalidad; únicamente, en un caso, dentro de las recetas castellanas, se detalla el tipo, que debe ser de lluvia ${ }^{62}$.

Las sustancias aditivas ${ }^{63}$, inexistentes como ya se ha dicho en la receta que analizamos, se suelen incorporar en los últimos compases del proceso ${ }^{64}$, aunque en ocasiones se suman al inicio del mismo. En la receta que aparece la amapola, ésta se pone sola en remojo, a primera hora del día, en una escudilla, y el líquido obtenido se sumará a aquellos otros que se obtuvieron de la maceración de otros ingredientes que fueron también puestos en remojo ${ }^{65}$. En la fórmula en que es mencionado el añilit ${ }^{66}$, éste se agrega al final, después de haber permanecido durante un tiempo en vino. La cáscara de granada aparece en dos recetas, en una se agrega a mitad del proceso, y lo hace junto con el vitriolo ${ }^{67}$, mientras que en la otra se incorpora al final ${ }^{68}$.

59. BNE, ms. 9226, “Recepta para tinta negra para papel y para pergamino", p. 19 y “Tinta negra", p. 71; Libro de los Oficios del monasterio de Guadalupe, Receta 2, "Recebta para tinta negra para papel y para pergamino", f. 202r-v (Libro de los oficios del monasterio de Nuestra Señora de Guadalupe, Volumen I..., p. 369).

60. BPR, ms. II/1393, "Tintas”, f. 1v; BNE, ms. 9226, "Recebta para tinta negra para papel y para pergamino", p. 35 y "Tinta negra", p. 71, "Para hazer tinta para escribir en toda perfección buena", p. 161; BRAH, ms. K-50, "Receta de tinta", f. 146v; Libro de los Oficios del monasterio de Guadalupe, Receta 1, "Regla para hacer tynta", ff. 201v-202r; Receta 3, "Reçebta para hazer tinta sin fuego para letra y punto grueso en pergamino", f. 203r-v; Receta 2, "Recepta para tinta negra para papel y para pergamino", f. 202r-v (Libro de los oficios del monasterio de Nuestra Señora de Guadalupe, Volumen I..., pp. 368-370).

61. BNE, ms. 9226, "Tinta negra", p. 71; "Tinta negra", f. 106 y "Tinta negra", p. 112.

62. BNE ms. 9226, "Para hacer tinta negra buena", p. 41.

63. BPR, ms. II/1393, "Tintas", f. 1v; BNE, ms. 9226, "Recepta para tinta negra para papel y para pergamino", p. 35; "Tinta negra", p. 71; "Tinta negra", p. 106 y "Tinta negra", p. 112, "Para hazer tinta para escribir en toda perfección buena", p. 161, "Para hacer tinta negra buena", p. 41; BUS, ms. 354, "Receta de tinta", f. 225v.

64. BNE, ms. 9226, "Tinta negra”, p. 106, "Para hacer tinta negra buena", p. 41, Libro de los Oficios del monasterio de Guadalupe, Receta 3, "Reçebta para hazer tinta sin fuego para letra y punto grueso en pergamino", f. 203r-v (Libro de los oficios del monasterio de Nuestra Señora de Guadalupe, Volumen I..., p. 370).

65. BNE. ms. 9226, "Tinta negra”, p. 106.

66. BNE. ms. 9226, "Tinta negra", p. 106.

67. BUS. ms. 354, "Receta de tinta", f. $225 \mathrm{v}$.

68. BNE. ms. 9226, "Tinta negra”, p. 19. 


\section{ConClusiones}

Como colofón del presente trabajo podemos reafirmar las ideas ya expresadas a lo largo del mismo.

La receta de tinta negra incluida en el manuscrito 94 del Fondo de Manuscritos del Archivo de Alba es una fórmula adscrita a la tipología de las metalogálicas, tipología de la que se desconoce con certeza cuándo empezó a usarse. A partir del siglo XII, la localización de fórmulas de esta modalidad resulta fácil, existiendo numerosos ejemplos de entonces, así como varios de siglos anteriores, Etimologías de San Isidoro, y entre los motivos de su aplicación, en lugar de las carbónicas, está el uso del nuevo soporte, el papel.

Ella como las recetas castellanas, analizadas en trabajos anteriores y comparadas aquí con ella, forman parte de la tradición de la Europa Occidental, derivado ello de la presencia de las nueces de agalla, tanino, frente al los frutos y cortezas, materias que aparecen en las adscritas al norte de Europa, así como, también, por la presencia de agua y vino, especialmente, el último, como disolvente frente a la cerveza que se aplicaba como tal en Alemania y otros lugares de su entorno.

La presencia de las nueces de agallas, tanto en la receta de la Casa de Alba como las castellanas, nos permite hablar de la influencia que tuvo en la escritura el mundo árabe, el cual venía usando dicha sustancia como tanino, en dicho ámbito, desde finales del primer milenio o principios del segundo, y lo venía haciendo de un modo continuado.

Las sales en unas y otras aparecen, estando la diferencia en la palabra o término con que se asigman, así en la que nos ocupa aparecen nombradas como "tierras", que, como ya hemos mencionado, las relacionamos, gracias a dos recetas, recogidas sendas en un legajo de un notario gallego, con la caparrosa o con una materia que tenía las mismas características de esta, mientras que en las castellanas se citan bajo los nombres de caparrosa, vitriolo, acije, etc., nombres genéricos de dos sulfuros, verde y azul, de los cuales el recomendable para las tintas es el verde, debido a los rasgos que le proporciona a esta.

El aglutinante, goma, la de la Casa de Alba incluye el habitual y, además, lo hace a secas, es decir, no incluye "arábiga".

El diluyente, agua, en esta ocasión aparece la excepción, en las castellanas el habitual es el vino, siendo dentro de este el más corriente la modalidad del blanco.

En el tema de los procesos, molturación, remojo, cocción y maceración, la receta de la Casa de Alba presenta ciertas matizaciones, algunas de las cuales también encontramos en las recetas castellanas, pues la casuística es muy amplia, así, por ejemplo, en esta, como en alguna de aquellas, encontramos el remojo en agua de las materias, en recipientes separados y distribuyéndose el líquido entre ellos. Mientras que la diferencia entre la receta objeto de estudio y las castellanas está en dos cocimientos sucesivos, el primero se produce después de la incorporación de las agallas y el segundo a continuación de la goma.

Con todo lo dicho, se puede afirmar que la receta incluida en el manuscrito 94, del citado archivo, es una fórmula más $\mathrm{y}$, comparada con las castellanas, presenta 
dos matizaciones a tener en cuenta: "las tierras", como expresión a través de la cual se refiere a las sales metálicas, y los sucesivos cocimientos.

\section{APÉNDICE DOCUMENTAL}

\section{Siglo XV.}

Receta de tinta metalogálica.

A. C. A. Sección Manuscritos, Ms. 94, fols. 91r-v

\section{Para fazer tinta buena prieta}

"Se toma onza y media de goma e dos onzas de agallas e dos onzas tierra ${ }^{69}$. Estas cosas sean molidas cada una sobre si y echadas cada una por si en agua una noche y un día, e después echa en una caldera una azumbre de agua y echa las agallas e ponla sobre el fuego e cueza esta agalla con el agua fasta que se gaste la mitad. Et después ponlo a esfriar e des que fuere frio echa la goma e ponlo sobre [tachadura] fuego e hierva e desque fuere frío echa la tierra meçiendola por que se mezcle bien grand pieça".

\section{Siglo XV.}

Receta de tinta.

Legajo del notario gallego, Álvaro Peres ${ }^{70}$.

Boa tĩta se deue faser en [e]sta guisa Cosjda

"Para hũu neto de tĩta, õça e medja de agalla; deiteredes medjo açunbre d'agua de chuuja e ferua fasta que mēgüe la metade cõ as ditas agallas quebradas. E despoys que asētado, sacar esta agua e deitarle ij õças de terra ou j ocça de caparrosa e pónase al sol dous djas. E ha de feruer en ola noua" $"$.

\section{Siglo XV.}

Receta de tinta.

Legajo del notario gallego, Álvaro Peres ${ }^{72}$.

69. Caparrosa, vitriolo, sulfuro o sales metálicas.

70. Tato Plaza, Libro de notas de Álvaro Pérez, notario de terra de Rianxo e Postmarcos (145), Consello da Cultura Galega e Ilustre Colegio Notarial da Coruña, Santiago de Compostela, 1999, p. 337.

71. Buena tinta se debe faser en esta guisa cosida: "Toma onza y media de agallas, desleírla en medio azumbre de agua de lluvia e hierva hasta que merme la mitad con dichas agallas quebradas. E después que está asentada, saca esta agua e añadirle dos onzas de tierra o una onza de caparrosa, e ponlas al sol dos días. E hacerla hervir en una olla nueva".

72. Tato Plaza, Libro de notas de Álvaro Pérez, notario de terra de Rianxo e Postmarcos (145), Consello da Cultura Galega e Ilustre Colegio Notarial da Coruña, Santiago de Compostela, 1999, p. 337. 
Que nõ seja cosjda

"Tomar hũu neto de vjno brãco e se teuer pũta de vjnagre tãto he mellor, e deitar en el as agallas quebradas e estē ao sol dous ou tres djas. E despoys deitarlle la terra ou caparrosa, aquello que virdes que rrequēre. A goma deitarla ēno tĩteyro"73.

\section{BiBLIOGRAFÍA}

Cárcel Ortí, María Milagros y Trenchs Odena, José, "La tinta y su composición. Cuatro recetas valencianas (siglos XV - XVIII)", Revista de Archivos, Bibliotecas y Museos, 82 (1979), pp. 415-426.

Córdoba de la Llave, Ricardo, "Un recetario técnico castellano del siglo XV, el manuscrito H - 490 de la Facultad de medicina de Montpellier", La España Medieval, 28 (2005), pp. 7-48.

Dioscórides, Plantas y remedios medicinales, introducción, traducción y notas de Manuel García Valdés, Biblioteca Clásica Gredos, Ed. Gredos, Madrid, 1998.

Doemer, M., Los materiales de pintura y su empleo en el arte, Ed. Reverte, Barcelona, 2005.

Feiner, Jahannes., Mysterium salutis: manual de teología como historia de la salvación, Ediciones Cristiandad, Madrid, 1973.

Fradejas Rueda, José Manuel, "De nuevo sobre los manuscritos del Libro de la caça de las aves de Pero López de Ayala", Lengua Viva: Homenaje a César Hernández Alonso, Universidad de Valladolid - Diputación de Valladolid, Valladolid (2008), pp. 1097-1115.

Galende Díaz, Juan Carlos, "La escritura en España durante el siglo XVI: Génesis y evolución de la caligrafía", Universidad Complutense de Madrid. Disponible en humanismo http://ww.tribunalqro,gob.mx/humaniverso/articulos. php?login_autor.juancarlos

García Cuadrado, Amparo, Las cantigas: El códice de Florencia, Universidad de Murcia, Murcia, 1993.

González-Alonso Martínez, Enriqueta, Tratado del dorado, plateado y su policromía: tecnología, conservación y restauración, Ed. Universidad Politécnica de Valencia, Valencia.

Hamel, Christopher de, Copistas e iluminadores. Artesanos Medievales, Ed. Akal, Madrid, 1997.

Hidalgo Brinquis, María del Carmen, "El papel de los manuscritos árabes e hispanoárabes: características materiales", Al-mahtutụtä̈ al- 'arabiyä̈ fì isbaniya wa al-Magrib, Ed. María Jesús Viguera, Concepción Castillo Castillo, Fundación El Legado Andalusí, Granada (2006), pp. 289-304.

73. Que no sea cosida: "Toma un poco de vino blanco e si tiene un poco de vinagre un tanto mejor, e echar en él unas agallas quebradas e este al sol dos o tres días. E después deja la tierra o caparrosa, aquella que veas que requiere. E goma déjala en un tintero". 
Klages, Federico, Tratado de química orgánica: Química orgánica sistemática / versión española por Vicente Gómez Aranda, Volumen 1, Parte 1, Ed. Reverte, Barcelona, 2005.

Kroustalis, Stefanos, "La Escritura y sus materiales, pigmentos, tintas e instrumentos", El soporte de la lengua, Coord. M. C. Hidalgo Brinquis, Nájera 2226 de septiembre 2003, Patronato de Santa María la Real de Nájera, Logroño (2008), pp. 133-166.

- " "Escribir en el siglo XVI, recetas de la tinta negra española", Torre de los Lujanes, Boletín de la Real Sociedad Económica Matritense de Amigos del Pais, 48 (2002), pp. 99-112.

Libro de los oficios del monasterio de Nuestra Señora de Guadalupe, Volumen I, dirigido y coordinado por M. L. Cabanes Catalá, Edita Secretaría General Técnica del Ministerio de Cultura, Subdirección General de Publicaciones, Información y Documentación, Junta de Extremadura, Consejería de Cultura y Turismo y Monasterio de Guadalupe, Badajoz, 2007.

Martínez Maganto, Julio, Ferrero Calabrig, José Lorenzo, Roldán García, Clodobaldo y Álamo Serrano, Jaime, "Los tituli picti, Estudio sobre el atramentum y su composición", Congreso Internacional Ex Baetica Amphorae, Vol IV, Conservas, aceite y vino de la Betica en el Imperio, Sevilla-Écija, 17 al 20 de diciembre de 1998, Ed. Gráficas Sol, 1221-1229.

Martin, Judy, Guía completa de caligrafía: técnicas y materiales, Ed. Akal, Madrid, 1996.

Morterero y Simón, Conrado, Apuntes de iniciación a la paleografía española de los siglos XII a XVII, Ediciones de Hidalguía, Madrid, 1979.

Pérez Herrero, Enrique y Rivero Suarez, Benedicta, Escritura manuscrita y procesal: Canarias en el siglo XVI, Anroart ediciones, Las Palmas de Gran Canaria, 2006.

Persee, “Anciennes recettes d'encre”, Bibliothèque de l'école des Chartes, 72, 1911.

Plaza, Fernando R., Libro de notas de Álvaro Pérez, notario de terra de Rianxo e Postmarcos (1457), Consello da Cultura Galega e Ilustre Colegio Notarial da Coruña, Santiago de Compostela, 1999.

Primo Yúfera, Eduardo, Química orgánica básica y aplicada: de la molécula a la industria, Vol. 1, Ed. Reverte, Barcelona, 1994.

Quetglas, Pere J., Elementos básicos de filología y lingüística latinas, Universitat de Barcelona, Barcelona, 2006.

Riesco Terrero, Ángel, Introducción a la paleografía y la diplomática general, Ed. Síntesis, Madrid, 2000.

Rodríguez Díaz, María Elena, "Técnicas de escrituras y del manuscrito", Historia de la técnica y de la ciencia en la corona de Castilla, tomo II, Edad Media (Coord. L. García - Ballester), Edita Junta de Castilla y León, Consejería de Educación y Cultura, Valladolid, 2002, pp. 589-618.

Romero Tallafigo, Manuel, Arte de leer escrituras antiguas, paleografía de lectura, Universidad de Huelva, Huelva, 2003. 
Ruiz García, Elisa, Manual de Codicología, Fundación Germán Sánchez Ruipérez, Ed. Pirámide, Madrid, 1988.

Theophilus, On Diver arts, Courier Dover Publications, Nueva York, 2012.

Vian Ortuño, Ángel, Introducción a la química industrial, Ed. Reverte, Barcelona, 2006.

Fecha de recepción del artículo: septiembre de 2014

Fecha de aceptación y versión final: enero de 2015 